\title{
PROGRAMAÇÃO MUSICAL NO TEATRO SANTA ISABEL
}

\author{
Marcos Tadeu Holler ${ }^{1}$ \\ Gustavo Weiss Freccia ${ }^{2}$
}

\section{RESUMO:}

Neste texto constam alguns resultados obtidos com a pesquisa em andamento de título $A$ música na imprensa em Desterro no Séc. XIX, sob o recorte temático referente à música nos teatros desterrenses durante o período imperial, em especial o Teatro Santa Isabel. O principal objetivo deste trabalho é apontar alguns exemplos de programas musicais encontrados nos jornais da época, incluindo não só o repertório apresentado como também os artistas envolvidos na atividade cultural da capital da província de Santa Catarina.

PALAVRAS-CHAVE:

História da Música no Brasil;

Pesquisa documental;

História de Santa Catarina;

História da Imprensa;

\section{Introdução}

Em 1831 o primeiro jornal de Desterro (atual Florianópolis) foi publicado, marcando o início da história da imprensa no estado de Santa Catarina. Chamava-se $O$ Catarinense e foi iniciativa de Jerônimo Coelho, um militar e líder liberal que chegou à Ilha de Santa Catarina com o intuito de "semear novas idéias" (BOITEUX apud PEDRO, 1995, p. 16). Este e sete outros periódicos surgiram até o ano de 1850, mas tiveram vida curta e estavam associados ao poder público de alguma forma. Foi apenas na segunda metade do séc. XIX que a imprensa teve atividade abundante, tendo surgido diversos periódicos ligados à oposição. Esses, especialmente, reservavam algumas de suas colunas ao jornalismo cultural, apresentando seções literárias, folhetins e notícias de várias partes do mundo, destinando parte de suas publicações aos anúncios de teor artístico.

Por meio de um levantamento de dados relativos à música nos periódicos de Desterro do período imperial, realizado no acervo de periódicos da Biblioteca Pública do Estado de Santa Catarina, encontraram-se noticiários e anúncios diversos, indo desde menções sobre música em literatura até divulgação de apresentações e a venda de instrumentos musicais. Esse levantamento faz parte de um projeto de mapeamento dos

\footnotetext{
${ }^{1}$ Doutor em Musicologia pela Universidade Estadual de Campinas (UNICAMP), professor da Universidade do Estado de Santa Catarina (UDESC). E-mail: mholler@udesc.br.

${ }^{2}$ Acadêmico do curso de Licenciatura em Música da Universidade do Estado de Santa Catarina (UDESC), bolsista PROBIC. E-mail: gustavowfreccia@gmail.com.
} 
acervos que contenham fontes sobre a história da música em Santa Catarina, sistematizando dados para futuras pesquisas.

Os dados referentes às apresentações musicais (que se teve acesso direto, diferente dos dados relativos à história dos teatros, recolhidos na literatura específica) tornaram-se mais abundantes nas duas últimas décadas do Império, a partir da inauguração do Teatro Santa Isabel, maior teatro de Desterro na época. Baseando-se no levantamento realizado nos jornais, o presente artigo enfoca a programação musical e os artistas que passaram pelo Teatro Santa Isabel nesse período.

\section{Contexto histórico e primeiros teatros em Desterro}

A vinda da Família Real para o Brasil em 1808 e a conseqüente independência do país, em 1822, logo teve suas influências na elite desterrense. As idéias de progresso da época eram evidentes até mesmo na imprensa. Nela, notícias internacionais tornaram-se mais acessíveis, fatos locais eram discutidos pelas publicações dos leitores e novidades políticas eram freqüentemente anunciadas.

O próprio desenvolvimento da imprensa em Desterro, surgida pouco antes da metade do século XIX, decorreu do crescimento de atividades ligadas ao comércio e ao transporte marítimo, tendo sido expressão de uma esfera pública burguesa, como afirma Joana Maria Pedro (1995). A cidade estava crescendo, e datam desta época o surgimento da Biblioteca Pública do Estado de Santa Catarina e dos primeiros teatros em Desterro, dentre outras evidências civilizatórias de preocupação do Império.

Notícias sobre a Independência do Brasil chegaram em Desterro com um mês de atraso, segundo informa Walter Piazza (2003). Embora o Brasil independente fosse um bom pretexto para a urbanização das províncias, principalmente de suas capitais, em Desterro isso custou a ser notável, apesar da liberdade de comércio externo ter existido e os desenvolvimentos artístico e científico terem sido afirmados e apoiados com a presença da Corte Portuguesa no Brasil.

Na capital da Província de Santa Catarina, durante a primeira metade do séc. XIX, eram abundantes os locais improvisados por iniciativa privada para a realização de espetáculos artísticos, evidenciando a falta de uma casa com este propósito. Este foi o caso da primeira referência à atividade teatral em Desterro chamada de Tragédia do Fayal, peça de autoria de Ovídio Saraiva de Carvalho e Silva (o Juiz de Fora), representada em 1817 num espaço adaptado em sua própria residência, no intuito de 
festejar a coroação de D. João VI de Portugal, e foi "acompanhada da mais harmoniosa música desta ilha" (CABRAL, 1972, p. 142). Iniciativas similares estiveram vinculadas às Sociedades Dramáticas Particulares (ou S. D. P., abreviação que os próprios jornais da época utilizavam), que eram não só amadoras como fechadas e elitistas (FABRIN, 2002). Foram essas sociedades que impulsionaram a vida cultural na cidade, tendo sido o Juiz de Fora o pioneiro.

A maior e também mais importante casa de espetáculos em Desterro até 1869 foi o Teatro São Pedro de Alcântara. Antes dele têm-se indicações esparsas de casas por iniciativa das S. D. P. que não duraram muito tempo e sobre elas há poucas informações, limitadas pelo fato de que a imprensa em Desterro se solidificou apenas na segunda metade do séc. XIX, como afirma Cabral (1972). As primeiras notícias sobre a existência desse teatro datavam de 1845 e 1846, período em que o Casal Imperial o visitou. Sua lotação era de apenas 400 lugares, mas, como menciona Paulo Clóvis Schmitz (1994, p.13), "para a época - 1857, quando a cidade tinha em torno de 21 mil habitantes -, 400 lugares [era] uma boa capacidade".

O Teatro São Pedro de Alcântara foi destruído em 1869 para alargar a Rua da Paz (chamada atualmente de Tenente Silveira) onde se localizava (SCHMITZ, 1994). Esse teatro não correspondia mais à atividade cultural que estava se intensificando, embora tenha sido com ele que o gosto pelas artes se consolidou em Desterro e as reformas não tenham sido poucas. Schmitz (1994) faz referência ao jornal O Cruzeiro do Sul (16/09/1856), que elogiava o teatro que São José possuía, lamentando a situação dos espaços destinados a espetáculos em Desterro, desejando que a capital tivesse um teatro igual àquele da cidade vizinha (chamado hoje de Teatro Adolfo Mello).

Entre a desativação do Teatro São Pedro de Alcântara até o ano 1875 não houve teatro profissional em Desterro, o que incentivou o surgimento de novos espaços alternativos para suprir a grande quantidade de S. D. P. que estavam sendo formadas. Deve-se lembrar que o teatro era um dos poucos meios de diversão da população no período imperial. Nas palavras de Schmitz (1994, p. 21), “o teatro era o ponto de encontro de pessoas jovens e importantes das cidades e o local onde se realizavam as festividades cívicas e sociais", justificando a necessidade de novos espaços para que os espetáculos ocorressem.

\subsection{O Teatro Santa Isabel}


Depois do Teatro São Pedro, a próxima casa de espetáculos seria inaugurada apenas no ano de 1875 , embora sua construção começasse a ser planejada em 1854, por iniciativa da Sociedade Empreendedora formada na época. Esta casa se chamaria Teatro Santa Isabel, nome dado em homenagem à Princesa Isabel, filha de D. Pedro II (SIMON, 1994).

Apenas formada a Sociedade Empreendedora, as ações dos sócios começaram a ser cobradas. Os sócios do Teatro São Pedro de Alcântara aos poucos foram deixando de investir em sua reforma para concentrar recursos na construção do novo teatro e artistas que passaram por Desterro também incentivaram a construção do Teatro Santa Isabel (SCHMITZ, 1994).

A construção do Teatro Santa Isabel teve uma conturbada trajetória de obras e paralisações durante 18 anos desde o lançamento da pedra fundamental até sua inauguração. Por algum tempo a Sociedade Empreendedora e seus acionistas estiveram parados, não dando crédito para o pagamento das dívidas adquiridas com o Governo, que colocou o prédio a leilão. Como coloca Cabral (1972, p. 149), "foi nessa ocasião que o Governo tomou conta do patrimônio e da obra, pois a ninguém interessou ficar com as ruínas nem com as contas.”. Fabrin (2002) aponta este fato como o primeiro estímulo à construção de um teatro advindo de iniciativa governamental em Desterro.

$\mathrm{Na}$ inauguração do Teatro Santa Isabel, acontecida no dia 7 de setembro de 1875, compareceram mais de mil pessoas, conforme o jornal $O$ Conservador do dia 11 de setembro de 1875. Dentre a programação houve apresentações das sociedades musicais Filarmônica Comercial e Santa Cecília, e da cantora Hassini.

O Teatro Santa Isabel, o maior e mais idealizado de Desterro durante o Império, teve seu nome mudado para Teatro Álvaro de Carvalho em 2 de julho de 1894, no mesmo ano que Nossa Senhora do Desterro passou a ser chamada de Florianópolis (quinto ano do período republicano). Este nome, além do rompimento com a monarquia extinta, representou uma homenagem ao primeiro dramaturgo catarinense, morto na Guerra do Paraguai.

\section{A programação musical no Teatro Santa Isabel}

Desterro, assim como o restante do Brasil a partir da vinda da Família Real, estava exposta às influências advindas do Rio de Janeiro. Durante o século XIX, especialmente na segunda metade, era comum que artistas que viessem de lá ou que 
para lá fossem excursionassem também pelo sul do Brasil. Essas notícias tornaram-se evidentes com a imprensa desterrense que estava se desenvolvendo, especialmente com os periódicos ligados ao partido liberal.

Quando se tratava da aparição de célebres artistas na capital da província de Santa Catarina, a imprensa não só os divulgava como muitas vezes trazia comentários sobre os espetáculos realizados. Nem sempre os autores das críticas compartilhavam as mesmas idéias, como foi o caso das opiniões sobre Rosa Villiot, cantora vinda com a companhia de ópera cômica do Rio de Janeiro, dirigida por Braga Jr. Enquanto o jornal A Regeneração tecia elogios à "sublime" cantora e um leitor dedicava uma poesia à “simpática atriz Rosa Villiot” (A REGENERAÇÃO, 09/01/1885), Cruz e Souza, redator d'O Moleque, sob o pseudônimo K-Boclo, publicava um de seus triolets ${ }^{3}$ ironizando a qualidade de voz da cantora, devido à sua idade (O MOLEQUE, 15/01/1885). Esses comentários ainda revelavam a reação do público ou lamentavam a falta dele.

A maioria dos concertos ocorridos em Desterro no século XIX resumiu-se às duas últimas décadas do Império, a partir da inauguração do Teatro Santa Isabel. Isso não significa que a atividade musical na cidade era inexistente, já que se têm notícias de sociedades musicais locais bastante ativas, peças teatrais "ornadas de música", espetáculos circenses com ouverture ou sinfonia no início, além de missas cantadas, anúncios de aulas de música, venda de partituras e instrumentos musicais, para citar alguns exemplos. Dentre os concertos, no entanto, os exemplos mais notáveis encontrados nos jornais envolviam artistas solo ou companhias líricas que ofereciam operetas ou zarzuelas ${ }^{4}$ completas e cenas ou atos inteiros de óperas consagradas em seus programas, conforme o gosto musical vigente no Rio de Janeiro nessa época.

O primeiro concerto no Teatro Santa Isabel foi realizado no dia 26 de setembro de 1875 pelas irmãs Maria e Carlota Hassini, artistas que haviam participado também da inauguração do teatro, semanas antes. O jornal O Conservador de 22 de setembro 1875 divulgou o programa deste concerto, com o qual as artistas se despediam de Desterro. Dentre as peças apresentadas constaram uma grand ouverture, a valsa Il Bacio de Arditi, o romance Non Torno de Mattei, o duo Le Roi Carotte de Offenbach (onde as artistas também dançariam), uma cena e ária da ópera Freischütz de Weber, a ária do terceiro ato de La Favorita de Donizetti, entre outras cançonetas e peças.

\footnotetext{
3 "Triolé s.m. Pequeno poema de forma fixa, oriundo do medievalismo francês. Consta de estrofes de oito versos, em duas rimas, com a seguinte disposição: abaaabab. O $1^{\circ}$, o $4^{\circ}$ e o $7^{\circ}$ versos são iguais". (HOUAISS, 1979, p. 849).

4 “Zarzuela s.f. Teatr. Pequeno drama lírico espanhol, caracterizado pela alternância de uma parte declamada e outra cantada”. (HOUAISS, 1979, p. 892).
} 
Os programas musicais dos artistas solo freqüentemente apresentavam adaptações sobre canções conhecidas, especialmente sobre motivos de óperas italianas. Estas adaptações eram chamadas de variações ou fantasias e sobre elas, após mencionar a programação do flautista virtuose M. A. Reichert, que se apresentou em Desterro no ano de 1867, Cabral afirma:

\begin{abstract}
O que se nota nesses concertistas [...], não é a inclusão nos seus programas de números de alta música. Preferiam os trechos de óperas e canções populares para demonstrarem habilidade e destreza manual na execução destas variações que constituíam o forte dos artistas - e nisto, ao que parece, se resumia a classe dos executantes que nos visitaram, já que nenhum programa demonstra preocupações na escolha de trechos e estudos clássicos, capazes de revelar a têmpera dos verdadeiros mestres. Também, seria exigir demais, não só para a nossa platéia do Desterro, mas também para outras de meios maiores. Todas elas apreciavam a fluidez destas "variações", sobre motivos que conhecia ou descobria nelas, de músicas fáceis ao ouvido, donde ganhavam o coração sentimental dos espectadores. Estudos clássicos, ouvertures, sinfonias, músicas descritivas nem sempre eram compreendidas e às platéias de então, era mister apresentar programas mais modestos. (CABRAL, 1951, p. 24).
\end{abstract}

Embora Cabral afirme que nenhum programa escapava dessa tendência, foram encontradas referências apresentando "estudos clássicos", como a do pianista alemão Alberto Friedenthal, que tocou Scarlatti, Chopin, Schumann, Mendelssohn, Liszt e até mesmo Rubinstein (A REGENERAÇÃO, 22/06/1888), e da pianista brasileira Luiza Leonardo, discípula particular de Anton Rubinstein e primeiro prêmio no Conservatório de Paris (A REGENERAÇÃO, 20/10/1888). Luiza Leonardo tocou, no piano cedido pelo Coronel Gama D’Eça, peças de Chopin, Mendelssohn, do americano Gottschalk e de outros compositores em seu concerto no Teatro Santa Isabel.

Exemplos condizentes à tendência das adaptações de temas conhecidos foram os programas do maestro e violinista italiano Vicenzo Cernicchiaro, vindo do Rio de Janeiro acompanhado pela prima donna Marieta Siebs, que acabara de cantar na estréia nacional da ópera La Gioconda de Ponchielli. O jornal A Regeneração do dia 7 de novembro de 1883 comparou o instrumentista a Paganini e Sarasate. Alguns dias antes, em 3 de novembro, o jornal $O$ Despertador anunciava a apresentação do clarinetista português Daniel Augusto Barreto, que tocaria uma fantasia sobre motivos da ópera Rigoletto, acompanhado pela orquestra.

No ano seguinte, no dia 21 de junho, o jornal $O$ Despertador publicou o programa do clarinetista, violonista e barítono cego Nicolas Campos, que seria acompanhado por uma orquestra sob a direção do maestro Roberto Grant. Além de ter 
cantado árias de Donizetti e Verdi, o músico tocou uma fantasia com variações para violão sobre motivos da ópera I Puritani de Bellini, além de uma fantasia concertante para clarinete com acompanhamento de orquestra sobre temas de Cavallini.

Companhias líricas de diversos lugares ocasionalmente passavam pela capital da Província e, antes de seguirem viagem, também deram alguns concertos no Teatro Santa Isabel. Foi o caso da companhia lírica francesa dirigida por Felix Verneuille, que contava com 22 artistas e estreou com a representação da opereta Les Cloches de Corneville de Planquette, em setembro de 1880. Comentando a estréia, o jornal $A$ Regeneração (12/09/1880) se queixava da falta de instrumentos para completar a orquestra tal como a peça exigia. Dentre as apresentações, constaram diversas operetas e óperas de Offenbach como La Grand Duchesse, Orphée aux Enfers, La Vie Parisienne entre outras, de outros autores, como La Fille du Régiment de Donizetti e La Fille de Mme. Argot de Lecocq.

Outro exemplo encontrado diz respeito à companhia lírico-cômica italiana com direção de Fausto Scano, que continha óperas, operetas e farsas de compositores como Lecocq, Planquette, Donizetti, Offenbach e Suppé em seu repertório. Essa companhia perdurou cerca de três meses e meio em Desterro, no final do ano de 1882. Meses depois, mais artistas italianos se apresentariam na capital da Província de Santa Catarina, desta vez dirigidos pelo desterrense José Brasilício de Souza, e dentre o repertório apresentado constaram excertos da ópera Il Guarany de Carlos Gomes, Il Trovatore de G. Verdi e até mesmo trechos da ópera $O$ Ermitão de Muquem, do próprio José Brasilício.

De maio a junho de 1884 esteve em Desterro a companhia italiana de ópera do diretor Alfredo Rota. Segundo o jornal O Despertador de 7 de maio de 1884, a estréia da companhia, que contou com as operetas Serafim, o Grumete e As Mulheres Guerreiras, foi muito aplaudida, especialmente na habanera cantada pela Sra. Zaccon. Entre outros números que a companhia apresentou constaram a ópera em três atos Crespino e la Comadre de Ricci, a ária Una Voce Poco Fa da ópera Il Barbiere di Siviglia de Rossini (cantada pela Sra. Zaccon), trechos da opereta Les Cloches de Corneville e uma ária e um dueto da ópera Don Pasquale de Donizetti.

A companhia lírica do Rio de Janeiro, dirigida por Braga Jr., contava com 65 artistas e estreou no Teatro Santa Isabel no início do ano 1885 com a opereta $O$ Sino do Eremitério, do maestro português Alvarenga. Essa companhia apresentou ainda a opereta La Fille de Mme. Argot, D. Juanita de Suppé, A baronesa de Caiapó de 
Offenbach, Mandarim e sobre esses espetáculos o jornal A Regeneração publicou alguns comentários.

A referência mais recente encontrada sobre apresentação de uma companhia lírica no Teatro Santa Isabel ainda no Império diz respeito a uma companhia italiana dirigida por Luiz Milone, que contava com apenas 10 artistas e se apresentou em junho de 1888. Entre as publicações de programas e crônicas, percebeu-se maior presença do compositor Giuseppe Verdi, com referências à ária de tenor Di quella pira da ópera Il Trovatore e trechos das óperas La Traviata e Un Ballo in Maschera. Além dessas peças foram apresentados, novamente, excertos da opereta Les Cloches de Corneville, trechos de Bocaccio de Suppé, da ópera Il Barbiere di Siviglia, entre outras.

Exemplos de apresentações musicais realizada apenas com artistas locais não eram muito freqüentes. Um dos exemplos mais interessantes foi a iniciativa da S. D. P. Fraternal Beneficente que, dirigida por José Brasilício de Souza, realizou uma montagem da peça Niniche em junho de 1880, reapresentada no aniversário da independência naquele ano. Sobre este número, publicou-se que se tratava de uma “engraçada composição dramática de Alfredo Henrequim e Alberto Millaut, posta em música pelo maestro Mario Bollard, traduzida para o português por Arthur Azevedo" (A REGENERAÇÃO, 20/05/1880, p. 1). O mesmo grupo apresentou, no mês de agosto do mesmo ano, uma opereta do próprio maestro Brasilício chamada Os Namorados de Minha Mulher, sobre a qual o jornal A Regeneração teceu diversos elogios.

Além dos exemplos de artistas solo e companhias líricas, encontrados em maior número na consulta aos jornais, outros exemplos relativos à música merecem ser citados. Por exemplo, uma versão em português parodiando La Traviata, chamada Cenas da vida Fluminense, que foi apresentada em abril de 1888 por uma companhia dramática carioca, dirigida por Cardoso da Motta, com os atores cantando fragmentos musicais originais de Verdi (A REGENERAÇÃO, 1888).

Em outras situações o Teatro Santa Isabel também comportou música, como foi o caso de uma festa de caridade realizada em novembro de 1880 , onde participaram as sociedades musicais Fraternal Beneficente e Guarani e um amador tocou variações para clarinete e flauta. Nos festejos aos 61 anos do Padre Paiva, em julho de 1882, realizouse de um concerto instrumental e vocal onde compareceram, entre outras personalidades, José Brasilício de Souza, Francisco Costa e Adolfo Mello. Em uma soirée e concerto vocal e instrumental realizado por professores e amadores desterrenses que almejavam verter fundos para o Liceu de Artes e Ofícios, foi apresentada a 
ouverture de Semiramis (provavelmente Semiramide de Rossini), transcrita para piano a oito mãos.

\section{Considerações finais}

Como se pôde perceber pelas informações nos jornais, a atividade teatral em Desterro demorou a se desenvolver, sendo o primeiro teatro da cidade o Teatro São Pedro de Alcântara, que só surgiu pouco antes da metade do século XIX. Antes, durante e mesmo depois da construção do Teatro Santa Isabel, em 1875, eram abundantes os espaços adaptados para quaisquer fins artísticos na cidade, da mesma forma que ocorria com os espetáculos antes da existência das casas de ópera em outros locais do Brasil, no século XVIII, como menciona Budasz (2006). O autor afirma ainda que "para uma sociedade lutando para manter sua identidade européia numa paisagem tropical e selvagem, uma casa de ópera era evidência de sua condição civilizada e educada"

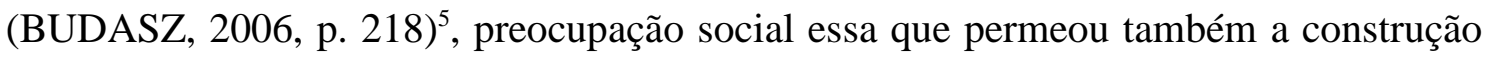
dos teatros catarinenses no período imperial, sendo compartilhada pelo jornal $O$ Argos do dia 8 de março de 1861 no que diz respeito à existência de teatros nas cidades para que fossem avaliadas sua moral e civilização.

Nos programas do Teatro Santa Isabel encontrados nos jornais percebe-se a presença freqüente da música erudita européia, com a predominância da ópera italiana. Mas, como era comum nos centros urbanos do Brasil no final do século XIX, encontraram-se também referências à música francesa e espanhola, com as operetas e zarzuelas, respectivamente. As peças européias apresentadas pelas companhias brasileiras nem sempre estavam traduzidas para o português, apesar da iniciativa do militar espanhol José Amat, em meados do século XIX, de difundir a música lírica em vernáculo e criar uma ópera nacional no Rio de Janeiro, como menciona Castagna (2003).

O gosto musical em Desterro seguia o gosto nacional, que correspondia às influências portuguesas e que o Rio de Janeiro, por sua vez, representava, sendo a capital do Brasil no Império e também o grande centro operístico e musical do país no séc. XIX. O público desterrense que freqüientava o teatro (provavelmente a elite que também lia os jornais) apreciava o que estava acessível, com os artistas que se dispunham a apresentar seus espetáculos.

\footnotetext{
${ }^{5}$ Tradução dos autores.
} 
Embora a programação musical contivesse, na maioria das vezes, música de concerto européia, o Teatro Santa Isabel comportou outros momentos em que a música esteve envolvida, como comemorações cívicas onde sociedades musicais tocavam o Hino Nacional ou peças teatrais “ornadas de música”. Além do envolvimento das sociedades musicais, alguns compositores locais tinham oportunidade de mostrar seu trabalho, como o exemplo das óperas $O$ Ermitão de Muquem e Os Namorados de minha Mulher de José Brasilício de Souza citados nesse artigo.

$\mathrm{O}$ intuito deste texto foi apontar alguns exemplos dentro do repertório e programação musical acontecidos no Teatro Santa Isabel no final do séc. XIX em Desterro; este trabalho terá continuidade no próximo semestre, o que possibilitará um maior aprofundamento na abordagem do tema.

\section{REFERÊNCIAS BIBLIOGRÁFICAS}

BUDASZ, Rogério. Opera and musical theater in eighteenth-century Brazil: a survey of early studies and new sources. Firenze: Accademia Nazionale di Santa Cecilia, 2006

CABRAL, Oswaldo Rodrigues. A música em Sta. Catarina no século XIX. Florianópolis: s.e., 1951.

Nossa Senhora do Desterro: memória. Florianópolis: Imprensa da Universidade Federal de Santa Catarina, 1972.

CASTAGnA, Paulo. A Imperial Academia de Música e Ópera Nacional e a ópera no Brasil no século XIX. São Paulo: UNESP, Instituto de Artes, 2003.

CATÁLOGO de Jornais Catarinenses: 1850-1989. Florianópolis: s.e., 1990.

FABRIN, João Baptista Giachini. Grandes casas, novidades e curiosidades: uma análise do teatro e outros espetáculos em Nossa Senhora do Desterro na época imperial. Florianópolis: UDESC, Centro de Ciências Humanas e da Educação, 2002.

PEDRO, Maria Joana. Nas tramas entre o público e o privado: a imprensa de Desterro, 1831-1889. Florianópolis: Editora da UFSC, 1995.

HOUAISS, A. (coord). Pequeno Dicionário Enciclopédico Koogan Larousse. Rio de Janeiro: ed. Larousse do Brasil, 1979.

SCHMITZ, Paulo Clóvis. O Teatro Álvaro de Carvalho. In: SCHMITZ, Paulo Clóvis (org.); et al. Pequena história do Teatro Álvaro de Carvalho. Florianópolis: Paralelo 27: FCC, 1994.

SIMON, Lílian Mendonça. Do antigo Teatro Santa Isabel ao Teatro Álvaro de Carvalho: transformações ao longo do tempo. In: SCHMITZ, Paulo Clóvis (org.); et al. Pequena história do Teatro Álvaro de Carvalho. Florianópolis: Paralelo 27: FCC, 1994. 
JORNAIS:

A Regeneração. Publicado duas vezes por semana e depois diariamente, ente $1868 \mathrm{e}$ 1889.

O Argos da Província de Santa Catarina. Periodicidade semanal, publicado de 1856 a 1862.

O Conservador. Publicado duas vezes por semana e depois três vezes por semana entre 1871 e1889.

O Despertador. Publicado duas vezes por semana entre 1863 e 1885.

O Moleque. Periodicidade semanal, publicado de 1884 a 1885. 